\title{
Congenitally corrected transposition of great arteries: a case series of five unoperated African children
}

Bernard Obongonyinge* (D), Judith Namuyonga, Hilda Tumwebaze, Twalib Aliku, Peter Lwabi and Sulaiman Lubega

\begin{abstract}
Background: Congenitally corrected transposition of great arteries (ccTGA) is rare. It is commonly associated with ventricular septal defect (VSD), pulmonary stenosis and heart block. Early anatomic repair is recommended between 3 and 6 months of age to prevent development of tricuspid valve regurgitation and systemic right ventricular failure.
\end{abstract}

Case presentation: We retrospectively identified five cases of ccTGA. Cases were between one and 13 years of age. All the cases were unoperated. Four of the five cases had associated intracardiac defects/complications. These included: VSD, pulmonary stenosis, tricuspid valve regurgitation, right ventricular systolic dysfunction and heart block.

Conclusion: These cases demonstrate the challenges of access to early diagnosis and surgery in a low resource setting. This delay in anatomic repair leads to complications of tricuspid valve regurgitation and systemic right ventricular failure.

Keywords: Case series, Heart block, ccTGA, Systemic right ventricle, Tricuspid regurgitation

\section{Background}

Congenitally corrected transposition of great arteries (ccTGA) is a rare congenital cardiac malformation. It accounts for approximately $0.05 \%$ of congenital cardiac anomalies [1]. In a 7-year review of congenital heart disease (CHD) at the Uganda Heart institute, ccTGA accounted for $0.14 \%$, while D-TGA (dextro-transposition of the great arteries) accounted for $0.7 \%$ of all the CHD [2]. This anomaly arises from Left (Levo) looping of the developing heart tube [3]. In situs solitus, Levo-looping brings the morphological left ventricle (LV) to lie on the right connected to pulmonary artery and the morphological right ventricle (RV) to lie on the left connected to the aorta [3].

ccTGA is associated with conduction, physiological and anatomical abnormalities. Ninety percent of patients will have a cardiac abnormality [1]. The commonest anatomic cardiac abnormalities include VSD, pulmonary stenosis and abnormalities of the tricuspid valve [4]. Conduction defects

\footnotetext{
* Correspondence: egaru2ob@gmail.com

Uganda Heart Institute, Mulago Complex, Kampala, Uganda
}

include heart block and supraventricular tachyarrhythmias [5]. Physiologically, absence of early corrective surgery leaves the right ventricle as the systemic ventricle leading to progressive RV systolic dysfunction. Progressive RV fibrosis, presence of tricuspid valve regurgitation and univentricular pacing of the morphological left ventricle lead to $R V$ systolic failure $[1,6,7]$. Clinical presentation depends on the concomitant cardiac defects. In patients with nonrestrictive VSD, early anatomic repair is recommended between 3 and 6 months of age to prevent the deleterious effect of a systemic RV [8]. However, in our low resource setting, cost and lack of access to corrective surgery delays corrective surgical repair as seen in these cases.

\section{Case presentations \\ Objective}

To describe the associated intracardiac defects and complications in a series of five unrepaired ccTGA cases.

(c) The Author(s). 2020 Open Access This article is licensed under a Creative Commons Attribution 4.0 International License, which permits use, sharing, adaptation, distribution and reproduction in any medium or format, as long as you give appropriate credit to the original author(s) and the source, provide a link to the Creative Commons licence, and indicate if changes were made. The images or other third party material in this article are included in the article's Creative Commons licence, unless indicated otherwise in a credit line to the material. If material is not included in the article's Creative Commons licence and your intended use is not permitted by statutory regulation or exceeds the permitted use, you will need to obtain permission directly from the copyright holder. To view a copy of this licence, visit http://creativecommons.org/licenses/by/4.0/ The Creative Commons Public Domain Dedication waiver (http://creativecommons.org/publicdomain/zero/1.0/) applies to the data made available in this article, unless otherwise stated in a credit line to the data. 


\section{Inclusion criteria}

All cases of ccTGA in the cardiac congenital registry were included. The cases were consecutively included in the series.

\section{Methodology}

We retrospectively identified patients with ccTGA, who presented to Uganda Heart Institute from the year 2012-2020. The identified cases were contacted by telephone to come back for review. Each review included clinical examination, electrocardiography and trans-thoracic echocardiography (TTE). TTE was performed by a paediatric cardiologist. TTE was done using GE vivid S60N cardiac ultrasound: Key echocardiographic variables included: Associated VSD, pulmonary stenosis, degree of tricuspid valve regurgitation and right ventricular systolic dysfunction. Right ventricular function was assessed using tricuspid valve annular plane excursion (TAPSE). Cardiac MRI was not done in any of the cases due to its high cost in our setting. The study was approved by the ethics board of Uganda Heart Institute.

\section{Case 1}

A 13-year-old, male, a known patient of ccTGA was reviewed with a history of palpitations and exercise intolerance. He did not report any associated history of presyncope, syncope or cyanosis. His past medical history is significant for tachypnoea, diaphoresis and failure to gain appropriate weight. His symptoms were first noticed at the age of 1 month. A diagnosis of ccTGA was made at the age of 11 months. He often had quarterly hospital review after the onset of atrial fibrillation which started at the age of 6 years (He had previously been in sinus rhythm).

Clinical examination: Revealed a weight of $32 \mathrm{~kg}$ and height of $132 \mathrm{~cm}$ with BMI of 18.37. There was no pallor, pedal edema, central or peripheral cyanosis. His oxygen saturation was $99 \%$ in room air. He had an irregularly irregular pulse with a blood pressure of $91 / 64 \mathrm{mmHg}$. He had a left precordial bulge and a hyperactive precordium with an apex beat in the seventh intercostal space, anterior axillary line. He had a grade 3 pan systolic murmur at the apex radiating to the axilla. A tender hepatomegaly of 10 $\mathrm{cm}$ below the costal margin was noted. His 13th year annual review TTE showed ccTGA, grossly dilated left atrium, 'Ebsteinoid' displacement of the tricuspid valve with severe tricuspid valve regurgitation (Fig. 1) Severe Right ventricular dysfunction was also noted. He is currently on optimal doses of frusemide, spironolactone, digoxin, enalapril together with warfarin and amiodarone for atrial fibrillation with rapid ventricular response rate. His ECG showed no P waves, irregular R-R interval, ventricular response rate of 132 beats per minute (bpm) and partial RBBB. The diagnosis of atrial fibrillation with rapid ventricular response rate was made (ECG Figure 1). Key clinical, echocardiography and ECG data are summarised in Table 1 below.

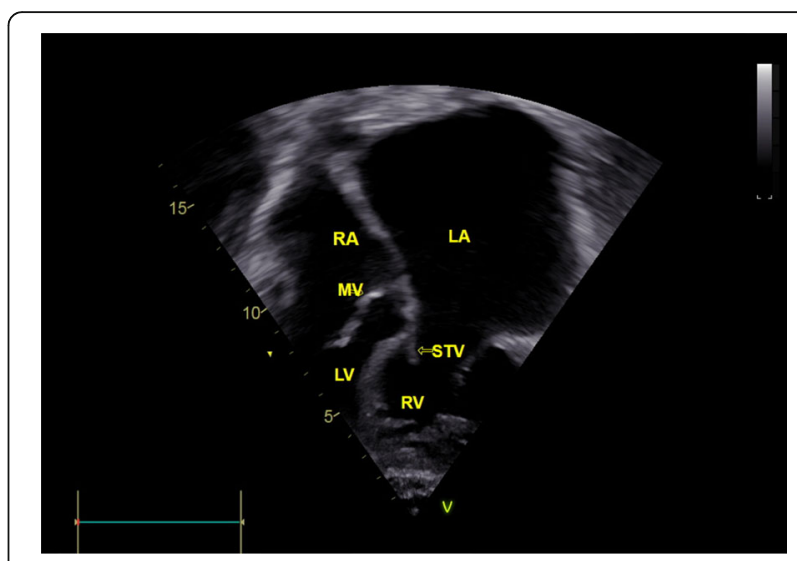

Left atrium (LA), left ventricle (LV), mitral valve (MV), right atrium (RA), right ventricle (RV), septal leaflet of the tricuspid valve (STV)

Fig. 1 Apical four chamber view showing a dilated left atrium, Ebsteinoid displacement of the tricuspid valve. Left atrium (LA), left ventricle (LV), mitral valve (MV), right atrium (RA), right ventricle (RV), septal leaflet of the tricuspid valve (STV)

\section{Case 2}

A six-year-old, male with ccTGA was seen with a history of exercise intolerance. He did not report any associated history of pre-syncope or syncope. He developed tachypnoea, diaphoresis and interrupted breastfeeding at the age of 1 month. A diagnosis of ccTGA was made at the age of 3 years and 3 months. He has had recurrent hospital admissions for severe pneumonia. Clinical examination: Revealed weight of $17 \mathrm{~kg}$ and height of $112 \mathrm{~cm}$ (underweight with BMI of $13.55, \mathrm{Z}$ score $-2 \mathrm{SD}$ ) There was no pallor, pedal edema, central or peripheral cyanosis. His oxygen saturation in room air was $98 \%$. He had a left precordial bulge and hyperactive precordium. There was a normal first heart sound, loud P2 component of the second heart sound and a grade 2 pan systolic murmur at the left lower sternal border. Other systemic findings were normal.

TTE showed ccTGA with mild mitral valve regurgitation through a cleft in the anterior leaflet. There was no tricuspid valve regurgitation. However, the septal leaflet of the tricuspid valve was seen straddling the interventricular septum and attaching to the septal surface of the morphological left ventricle (Fig. 2). There was a large inlet VSD of $26 \mathrm{~mm}$ in diameter (Fig. 3). The pulmonary valve was bicuspid with mild pulmonary valve stenosis. The ECG showed: normal P and QRS axis, the $\mathrm{P}$ rate was $100 \mathrm{bpm}$. There was complete atrioventricular dissociation with an ideo-junctional escape rhythm. The ventricular rate was $73 \mathrm{bpm}$. There were $Q R$ waves in lead V1 and RS in leads V5 and V6 (ECG Figure 2).

\section{Case 3}

A 3 year- old female, a known patient with ccTGA was brought back to the clinic with new onset complaints of exercise intolerance, profuse sweating. She had a diagnosis of ccTGA at the age of 1 year. She had been symptomatically 
Table 1 Showing clinical, ECG and echocardiographic characteristics of the cases

\begin{tabular}{|c|c|c|c|c|c|c|c|c|}
\hline \multicolumn{3}{|l|}{ Cases } & \multicolumn{5}{|l|}{ Echocardiography } & \multirow{2}{*}{$\begin{array}{l}\text { Electrocardiogram } \\
\text { Electrocardiogram }\end{array}$} \\
\hline Case & Symptoms & $\begin{array}{l}\mathrm{BMI} \\
\mathrm{SPO}_{2}\end{array}$ & $\begin{array}{l}\text { VSD } \\
\text { (size in } \mathrm{mm} \text { ) }\end{array}$ & $\begin{array}{l}\text { TR } \\
\text { Severity }\end{array}$ & $\begin{array}{l}\text { RV systolic } \\
\text { function }\end{array}$ & $\begin{array}{l}\text { Great } \\
\text { Arteries }\end{array}$ & $\begin{array}{l}\text { Septal wall } \\
\text { abnormalities }\end{array}$ & \\
\hline $\begin{array}{l}\text { Case } 1 \\
13 \text { Yrs }\end{array}$ & $\begin{array}{l}\text { Palpitation, } \\
\text { Exercise } \\
\text { intolerance }\end{array}$ & $\begin{array}{l}\text { BMI: } 18.37 \\
\mathrm{SPO}_{2}: 99 \%\end{array}$ & $\begin{array}{l}\text { Peri-membranous } \\
\text { VSD }(17 \mathrm{~mm})\end{array}$ & Severe & Severe & Normal & Yes & Atrial fibrillation \\
\hline $\begin{array}{l}\text { Case } 2 \\
6 \text { Yrs }\end{array}$ & $\begin{array}{l}\text { Palpitation } \\
\text { Exercise } \\
\text { intolerance }\end{array}$ & $\begin{array}{l}\mathrm{BMI}: 13.55 \\
\mathrm{SPO}_{2}: 98 \%\end{array}$ & $\begin{array}{l}\text { Inlet VSD (26 } \\
\mathrm{mm})\end{array}$ & None & Normal & Mild PS & none & $\begin{array}{l}\text { Complete heart block/ } \\
\text { junctional escape rhythm }\end{array}$ \\
\hline $\begin{array}{l}\text { Case } 3 \\
3 \text { Yrs }\end{array}$ & $\begin{array}{l}\text { dyspnoea, } \\
\text { diaphoresis }\end{array}$ & $\begin{array}{l}\mathrm{BMI}: 13.21 \\
\mathrm{SPO}_{2}: 96 \%\end{array}$ & $\begin{array}{l}\text { Inlet VSD (18 } \\
\mathrm{mm})\end{array}$ & Severe & Normal & $\begin{array}{l}\text { Moderate } \\
\text { PR }\end{array}$ & None & Junctional rhythm \\
\hline $\begin{array}{l}\text { Case } 4 \\
1 \text { Yr } 10 \\
\text { months }\end{array}$ & dyspnoea & $\begin{array}{l}\mathrm{BMI}: 17.78 \\
\mathrm{SPO}_{2}: 92 \%\end{array}$ & $\begin{array}{l}\text { Peri-membranous } \\
\text { VSD }(9 \mathrm{~mm})\end{array}$ & Moderate & Normal & Normal & None & Sinus rhythm \\
\hline $\begin{array}{l}\text { Case } 5 \\
8 \text { Yrs }\end{array}$ & none & $\begin{array}{l}\mathrm{BMI}: 15.93 \\
\mathrm{SPO}_{2}: 97 \%\end{array}$ & None & Mild & Normal & Normal & none & pre-excitation \\
\hline
\end{tabular}

Key: Bicuspid pulmonary valve with mild pulmonary stenosis $(P S)$, mitral valve regurgitation $(M R)$, pulmonary valve regurgitation $(P R)$, Tricuspid valve regurgitation $(T R)$, Years (Yrs)

controlled on frusemide and captopril. Her clinical examination revealed a sick child, who was diaphoretic, with weight, height and $\mathrm{SPO}_{2}$ of $10 \mathrm{~kg}, 87 \mathrm{~cm}$ and $96 \%$ respectively. She had a soft first heart sound at the apex, the P2 component of second heart sound was accentuated, with a pan systolic murmur at the apex radiating to the axilla and back. Her TTE showed ccTGA with a large non-restrictive inlet VSD of $18 \mathrm{~mm}$ in diameter. There was a new onset severe tricuspid valve regurgitation, moderate pulmonary valve regurgitation and mild mitral valve regurgitation (Fig. 4). Her ECG revealed: junctional tachycardia. The ventricular rate was $136 \mathrm{bpm}$ with RS in leads V5 and V6. There were retrograde $P$ waves embedded in the $T$ wave causing notching of the $\mathrm{T}$ waves (ECG Figure 3).

\section{Case 4}

A 1 Year and 10 months male child, seen at our centre with history of recurrent chest infection, tachypnoea

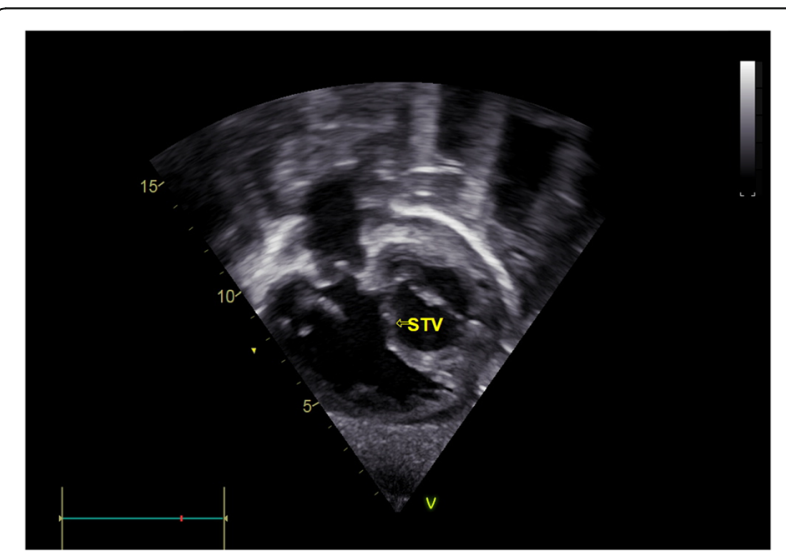

Fig. 2 Sub-costal view showing septal leaflet of the tricuspid valve (STV) straddling the inlet VSD since the age of 3 months. On examination his weight and height were $10 \mathrm{~kg}$ and $75 \mathrm{~cm}$ respectively, $\mathrm{SPO}_{2}=$ 92\%. His TTE showed ccTGA, a large peri-membranous VSD of $9 \mathrm{~mm}$ in diameter and moderate tricuspid valve regurgitation.

\section{Case 5}

An eight- year old, male child with an isolated ccTGA. He was first seen at the age of 6 months following an episode of pneumonia and an incidental finding of "cardiomegaly" on an A-P chest $\mathrm{x}$-ray. He has been asymptomatic since this initial diagnosis of ccTGA. Clinical examination: Revealed weight of $26.5 \mathrm{~kg}$ and height of $129 \mathrm{~cm}$ (underweight with BMI of 15.93) There was no pallor, pedal edema, central or peripheral cyanosis. His

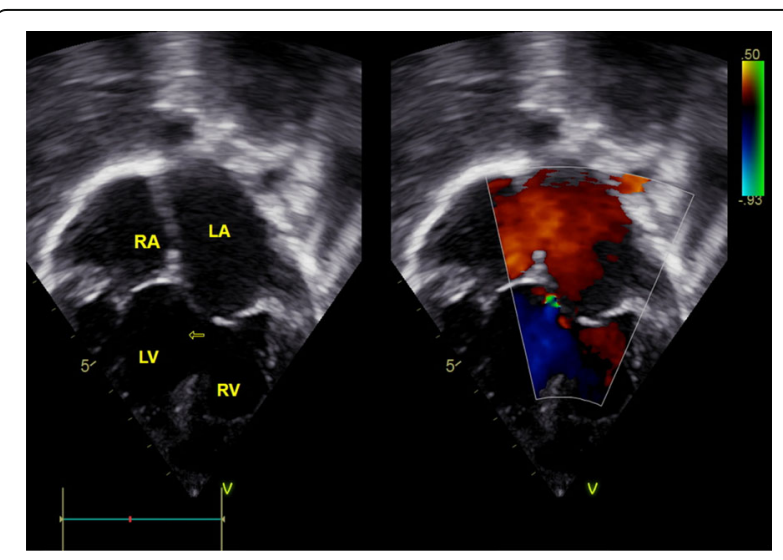

Left atrium (LA), left ventricle (LV), mitral valve (MV), right atrium (RA), right ventricle (RV), inlet VSD (arrow)

Fig. 3 Apical four chamber view showing: Reversed apical offset of the tricuspid valve and a large inlet VSD (arrow). Left atrium (LA), left ventricle (LV), mitral valve (MV), right atrium (RA), right ventricle (RV), inlet VSD (arrow) 


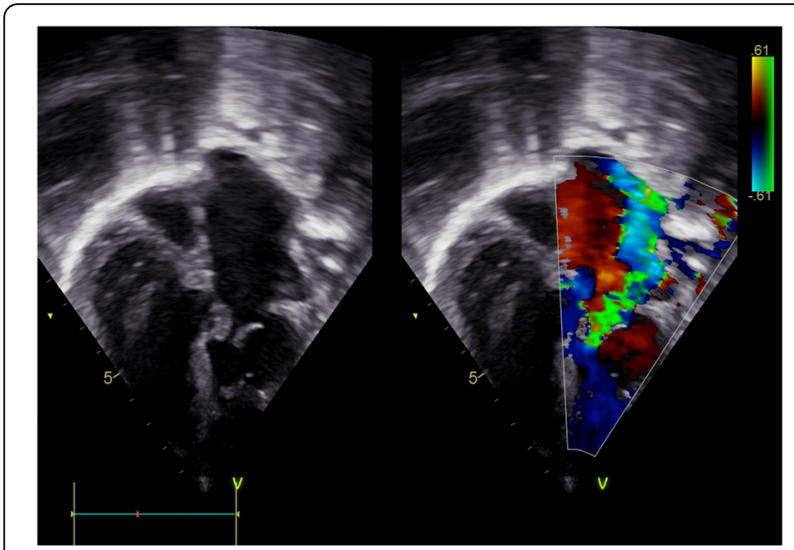

Fig. 4 Apical four chamber view showing tricuspid valve regurgitation

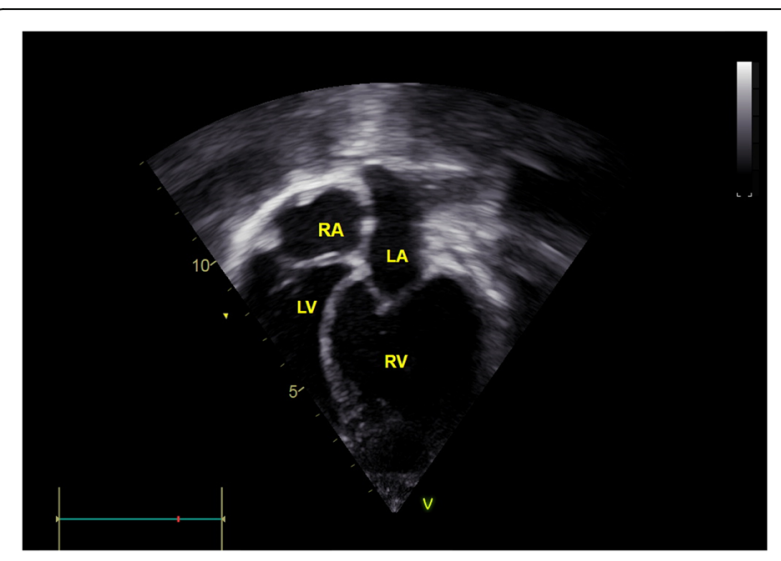

Fig 5 Apical four chamber view showing a dilated RV, intact interventricular septum with bowing to the right oxygen saturation in room air was $97 \%$. He had normal auscultatory findings. TTE still showed ccTGA without any other intracardiac defects. There was a mild tricuspid valve regurgitation, dilated systemic RV but with normal systolic function. We noted bowing of the interventricular septum towards the morphological left ventricle (Fig. 5). His ECG showed: sinus rhythm and preexcitation (ECG Figure 4). Other than ccTGA, none of cases reported other chronic illnesses However, they reported treatment for severe malaria.

\section{Discussion and conclusion}

Congenitally corrected transposition of great arteries (ccTGA) is a rare congenital cardiac malformation. It accounts for approximately $0.14 \%$ of congenital cardiac abnormalities in our setting [2]. Approximately, 90\% will have an associated cardiac defect [1]. Among the cases described above, the cardiac abnormalities included: Ebsteinoid anomaly of the tricuspid valve, tricuspid valve regurgitation, cleft mitral valve, pulmonary valve stenosis and ventricular septal defects. Ventricular septal defect (VSD) is present in approximately $84 \%$ of ccTGA $[1,6]$. Eighty percent of our cases had VSD. In ccTGA, VSD arises out of a defect created by a malalignment between the atrial and ventricular septa. Majority of the VSD are of peri-membranous type. However, in our series above, two of the five children had inlet VSD with the other two cases having a peri-membranous VSD. In patients with large inlet VSD, the AV valves may be at the same level. Therefore, the characteristic apical offset of the tricuspid valve may be absent [1].

Approximately, 90\% of patients will have tricuspid valve abnormalities leading to tricuspid regurgitation [1]. Four out of the five cases above had tricuspid valve regurgitation (TR). The mechanism of TR seen in case 1 above was due to 'Ebsteinoid' displacement of the tricuspid valve [1, 9]. On the other hand, TR seen in cases 2, 3 and 5 was attributed to tricuspid valve annular dilatation. Chronic TR is an important prognostic factor because it precedes systemic RV failure as seen in Case $1[9,10]$.

Pulmonary stenosis occurs in $53 \%$ of cases $[1,11]$. Obstruction may be at sub-valvular, valvular or supravalvular level [11]. Sub-valvular pulmonary obstruction is due to the origin of the pulmonary outflow between the gap created by atrial and ventricular septal malalignment. Mild Pulmonary valve stenosis as seen in case 2 is due to a bicuspid pulmonary valve.

The common types of clinical presentation include: symptomatic bradycardia, heart failure, and asymptomatic child or adult. Symptomatic bradycardia proceeds heart block as seen in case 2 and 3 above. In patients with normal atrial arrangement as seen in all the cases above, the conduction system is abnormal [5]. There is a discontinuity between a posteriorly located hypoplastic AV node and the bundle of HIS [5]. Usually, a second AV node located anteriorly gives rise to the bundle of HIS [1]. Progressive fibrosis of this second AV node leads to heart block as seen cases 2 and 3 [5]. Pre-excitation and atrial arrhythmias are common [12]. Atrial fibrillation noted in the first case is attributed to Ebsteinoid displacement of the tricuspid valve causing gross dilatation of the left atrium. Heart failure documented in the cases above is due to systemic RV volume overload from large non-restrictive VSD, tricuspid valve regurgitation and RV systolic dysfunction. Paucity of symptoms as seen in case 5 is due to the absence of associated intracardiac defects. Eventually, case 5 is predicted to develop progressive RV systolic dysfunction starting from the fourth decade of life leading to heart failure and sudden death $[1,12,13]$. This is due to a poor RV geometry, diminished RV coronary flow reserve, low resting right ventricular ejection fraction and progressive systemic RV fibrosis [12]. Cardiac MRI provides accurate assessment of systemic RV function and ventricular volumes [14]. However, in all the cases above, RV function was assessed using tricuspid 
annular plane systolic excursion (TAPSE). our study is therefore limited by our inability to carry out MRI due to its limited availability and high cost.

Medical treatment is dictated by the presence of associated intracardiac defects. Due to the presence of large VSD, the above patients have been on diuretics (frusemide, spironolactone) and angiotensin converting enzyme inhibitors (Captopril or enalapril) [3, 14]. In the absence of AV block, beta blockers have been used in patients with pulmonary stenosis, arrhythmias and for RV remodeling [14]. Due to the progressive nature of heart block, the above children have had annual ECG follow up [14]. Resource limitation and presence of an ideojunctional escape rhythm has obviated the need for urgent pacemaker insertion in case 2 above. Furthermore, early onset of complete heart block as seen in case 2 does not seem to increase risk of early death [5]. Univentricular pacing has been associated with worsening of systemic RV systolic function [5, 14]. This is due to LVRV desynchrony [5]. Therefore, cardiac resynchronisation therapy (CRT), will be of benefit to case 2 and 3 if they develop the following: $\mathrm{EF}<\_35 \%$, NYHA function Class II-IV and wide QRS complex >_150ms with a complete right bundle branch block [15].

\section{Impediment to cardiovascular care}

The Uganda Heart Institute (UHI) is the only national referral cardiac centre which provides comprehensive cardiovascular services. This is coupled with a weak referral and ambulance services [16]. Therefore, any Ugandan child from a remote health facility faces tremendous challenge of early identification and access to cardiovascular services at UHI [16]. Indeed, four of the five cases above all live near UHI. Great strides have been made in corrective surgery for CHD other than ccTGA at our centre. However, limitation in funding, critical surgical sundries and theatre space has created a large volume of unoperated cases with less priority placed on complex $\mathrm{CHD}$ such as ccTGA [16]. There is a well-developed CRT program mainly for the adult population albeit its high cost.

\section{Future surgery}

In patients with large VSD as above, surgery may involve 'anatomic' or 'physiological repair'. A conventional "physiological repair" involves repair of any intracardiac defects such as VSD. However, it leaves the RV as the systemic ventricle with a 20 year survival of approximately $50-80 \%[1,8]$. "Anatomic repair involves atrial switch (Senning or Mustard procedure) combined with arterial switch (double switch) or Rastelli procedure [1, 8]. This positions the $L V$ as the systemic ventricle with a 10 -year survival of $78-93 \%$ [8]. The ideal timing for the anatomic repair in patients with large non-restrictive VSD as seen in the above cases is between 3 and 6 months [8].
Since all our cases are older than 6 months of age, we propose the following: cases 2,3 and 4 with large nonrestrictive VSD should be assessed for suitability of LV to sustain systemic pressures before anatomic repair $[1,8]$. Any of the above cases with a deconditioned LV should undergo pulmonary artery banding (PA band) to control symptoms of heart failure and 'train' the LV followed by anatomic repair $[1,8]$. Case 5 with intact interventricular septum (IVS) should undergo PA band as well. In patients with intact IVS, PA band causes shift of the IVS towards the systemic RV. This leads to decrease in the distortion of the tricuspid valve and systemic RV dilatation [17]. Thus, PA band may improve functional status of patients [17]. Case 1 with severe tricuspid regurgitation, atrial fibrillation and systemic RV failure has opted for medical treatment only.

\section{Conclusion}

ccTGA is a rare cardiac malformation. In this series, it was associated with VSD, pulmonary stenosis and heart block. Furthermore, delay in anatomical correction led to the development of tricuspid valve regurgitation and right ventricular systolic failure.

\section{Supplementary information}

Supplementary information accompanies this paper at https://doi.org/10. 1186/s40949-020-00038-8.

Additional file 1: ECG Figure1. Showing atrial fibrillation. ECG Figure 2. Showing complete heart block with junctional rhythm. ECG Figure $\mathbf{3}$. Showing junctional tachycardia. ECG Figure 4. Pre-cordial leads showing pre-excitation

Additional file 2:.

Additional file 3:.

Additional file 4:.

Additional file 5:.

Additional file 6:.

\section{Abbreviations}

A-V: Atrioventricular; CCTGA: Congenitally corrected transposition of great arteries; IVS: Interventricular septum; LA: Left atrium; LV: Left ventricle; MV: Mitral valve; PS: Pulmonary stenosis; RV: Right ventricle; RA: Right atrium; STV: Septal leaflet of the tricuspid valve; TR: Tricuspid valve regurgitation; TTE: Transthoracic echocardiography; TV: Tricuspid valve; V-

A: Ventriculoarterial; VSD: Ventricular septal defect(s)

Acknowledgements

Not applicable

Authors' contributions

BO made substantial contribution to conception, data collection, design and drafting manuscript. JN, HT, TA, PL, SL revised the manuscript. LA, PL, SL: mentorship. All authors approved the final manuscript.

\section{Funding}

The study did not receive any funding.

Availability of data and materials

The datasets used and/or analysed during the current study are available from the corresponding author on reasonable request. 


\section{Ethics approval and consent to participate}

The study was approved by the ethics board of UHI.

\section{Consent for publication}

Not applicable.

\section{Competing interests}

The authors declare that they have no competing interests.

Received: 13 June 2020 Accepted: 10 September 2020

Published online: 01 December 2020

\section{References}

1. Hornung TS, Calder L. Congenitally corrected transposition of the great arteries. Heart. 2010;96(14):1154-61. https://doi.org/10.1136/hrt.2008.150532.

2. Namuyonga, J., et al, Patterns of congenital heart disease among children presenting to the Uganda Heart Institute, Mulago hospital A 7 year review, in African health sciences. 2020.https://www.ajol.info/index.php/ahs/article/ view/197855.

3. Lipczynska, M., et al., Response to: 'Contemporary management and outcomes in congenitally corrected transposition of the great arteries' by Kutty et al. Heart, 2018. 104(14): p. 1226. https://doi.org/https://doi.org/10. 1136/heartjnl-2018-313281.

4. Kutty, S., et al., Contemporary management and outcomes in congenitally corrected transposition of the great arteries. Heart, 2018. 104(14): p. 1148 1155. http://dx.doi.org/https://doi.org/10.1136/heartjnl-2016-311032.

5. Baruteau, A.E., et al., Cardiac Conduction System in Congenitally Corrected Transposition of the Great Arteries and Its Clinical Relevance. J Am Heart Assoc, 2017. 6(12). https://doi.org/https://doi.org/10.1161/jaha.117.007759.

6. Wallis, G.A., D. Debich-Spicer, and R.H. Anderson, Congenitally corrected transposition. Orphanet J Rare Dis, 2011. 6: p. 22. https://dx.doi.org/10. 1186\%2F1750-1172-6-22.

7. Brida, M., G.P. Diller, and M.A. Gatzoulis, Systemic right ventricle in adults with congenital heart disease: anatomic and phenotypic Spectrum and current approach to management. Circulation, 2018. 137(5): p. 508-518. https://doi.org/https://doi.org/10.1161/circulationaha.117.031544.

8. Hraska, V. and R.K. Woods, Anatomic repair of corrected transposition of the great arteries: the double switch. Semin Thorac Cardiovasc Surg Pediatr Card Surg Annu, 2019. 22: p. 57-60. https://doi.org/https://doi.org/10.1053/j. pcsu.2019.02.003.

9. Deshaies, C. and P. Khairy, The paradox of choice in the surgical management of congenitally corrected transposition: what should we do with all of these options supported by little evidence? Transl Pediatr, 2018 7(1): p. 5-8. https://dx.doi.org/10.21037\%2Ftp.2017.09.01.

10. Furuya, $T_{\text {., }}$ et al., Serial changes of tricuspid regurgitation after anatomic repair for congenitally corrected transposition. Eur J Cardiothorac Surg, 2020. https://doi.org/https://doi.org/10.1093/ejcts/ezaa022.

11. Cohen, M.S. and L.L. Mertens, Educational series in congenital heart disease: echocardiographic assessment of transposition of the great arteries and congenitally corrected transposition of the great arteries. Echo Res Pract, 2019. 6(4): p. R107-r119. https://dx.doi.org/10.1530\%2FERP-19-0047.

12. Andrade, L., et al., Mechanisms for heart failure in systemic right ventricle. Heart Fail Rev, 2019. https://doi.org/https://doi.org/10.1007/s10741-01909902-1.

13. Huhta, J., The natural history of congenitally corrected transposition of the great arteries. World J Pediatr Congenit Heart Surg, 2011. 2(1): p. 59-63. https://doi.org/https://doi.org/10.1177/2150135110387620.

14. Carazo, M., et al., Assessment and management of heart failure in the systemic right ventricle. Heart Fail Rev, 2020. https://doi.org/https://doi.org/ 10.1007/s10741-020-09914-2.

15. Hernández-Madrid A, et al. Arrhythmias in congenital heart disease: a position paper of the European heart rhythm association (EHRA), Association for European Paediatric and Congenital Cardiology (AEPC), and the European Society of Cardiology (ESC) working group on grown-up congenital heart disease, endorsed by HRS, PACES, APHRS, and SOLAECE. Europace. 2018;20(11):1719-53 https://academic.oup.com/europace/article/2 0/11/1719/4944677

16. Aliku TO, et al. Pediatric cardiovascular care in Uganda: current status, challenges, and opportunities for the future. Ann Pediatr Cardiol. 2017;10(1): 50-7 https://www.ncbi.nlm.nih.gov/pmc/articles/PMC5241845/.
17. Winlaw, D.S., et al., Intention-to-treat analysis of pulmonary artery banding in conditions with a morphological right ventricle in the systemic circulation with a view to anatomic biventricular repair. Circulation, 2005. 111(4): p. 405-411. https://www.ahajournals.org/doi/https://doi.org/10.1161/ 01.CIR.0000153355.92687.FA?url_ver=Z39.88-2003\&rfr_id=ori:rid:crossref. org\&rfr_dat=cr_pub\%20\%200pubmed.

\section{Publisher's Note}

Springer Nature remains neutral with regard to jurisdictional claims in published maps and institutional affiliations.
Ready to submit your research? Choose BMC and benefit from:

- fast, convenient online submission

- thorough peer review by experienced researchers in your field

- rapid publication on acceptance

- support for research data, including large and complex data types

- gold Open Access which fosters wider collaboration and increased citations

- maximum visibility for your research: over $100 \mathrm{M}$ website views per year

At BMC, research is always in progress.

Learn more biomedcentral.com/submissions 